OPEN ACCESS

Edited by:

Irene Messina,

Mercatorum University, Italy

Reviewed by:

Zhang Judy,

Xi'an Jiaotong University, China Margarete Boos,

University of Göttingen, Germany

${ }^{*}$ Correspondence:

Julia Straube

julia.straube@tu-braunschweig.de

Specialty section:

This article was submitted to

Organizational Psychology,

a section of the journal

Frontiers in Communication

Received: 13 July 2020 Accepted: 22 March 2021

Published: 16 April 2021

Citation:

Straube J and Kauffeld S (2021) Working Across Faultlines-Assessing Intersubgroup Communication in Teams. Front. Commun. 6:582937. doi: 10.3389/fcomm.2021.582937

\section{Working Across}

\section{Faultlines-Assessing Intersubgroup Communication in Teams}

\author{
Julia Straube* and Simone Kauffeld \\ Department of Industrial, Organizational and Social Psychology, Technische Universität Braunschweig, Braunschweig, \\ Germany
}

Communication between different subgroups is essential to group success, as different perspectives and knowledge need to be integrated. Especially when subgroups form due to faultlines, hypothetical dividing lines splitting a group into homogeneous subgroups, the resulting subgroups are vulnerable to negative intergroup processes. In this article, we evaluate different methods that have been used to trace communication between faultline-based subgroups and discuss challenges that researchers face when applying those methods. We further present the faultline communication index (FCl) as a novel approach to meet those challenges. We combine techniques from social network analysis with a behavioral process approach to trace communication processes between subgroups and provide scholars with tools to integrate in their own research. We illustrate this approach by observing and coding real time interactions in 29 organizational meetings. Results show that although functional faultline strength does not impact information exchange between subgroups, intersubgroup interactions positively relate to the quality of action plans defined at the end of a meeting. Managers and practitioners who work with diverse teams can be given guidance on how communication between subgroups evolves and how it can be shaped to become more effective. We further discuss implications for future research on communication between subgroups.

Keywords: group diversity, subgroups, interaction analysis, intersubgroup communication, faultlines

\section{INTRODUCTION}

In the year 1999, a Mars orbiter was lost in space because its navigation coordinates could not be transferred from a spacecraft team in Denver to a lab in California, causing a \$125 million loss to the NASA. An investigation into the causes revealed that a group of engineers had used the imperial measurement system, while the rest of the research group operated with the metric system.

This is just one of many examples where team communication has failed. However, not only in high impact teams responsible for multimillion-dollar projects communication is essential to group failure or success. Everyday work groups are equally affected by communication challenges. How can similar incidents be avoided? What can be done to ensure that information is sufficiently distributed within a group to produce reliable outcomes? How can we measure if a group successfully coordinates between different subgroups? Which types of groups are especially vulnerable to miscommunication?

Especially when group members refer to different conceptual worlds, as in the introductory example, reaching common ground can be a challenge (Huber and Lewis, 2010). Given that the 
workforce becomes increasingly diverse, teamwork represents working in an environment with individuals from different backgrounds, disciplines, or cultures. Many organizations rely on diverse teams that bring diverse perspectives into organizations and might outperform homogeneous groups due to their manifold skills and different sources of knowledge (e.g., Jehn et al., 1999; van Knippenberg et al., 2004; Horwitz and Horwitz, 2007). Besides the opportunities that different perspectives and diverse knowledge within a work group bring to group and organizational success, a central element is the integration of these different perspectives. Especially when a group falls into functional subgroups, i.e., smaller units within the same group separated by certain functional features or affiliations (e.g., discipline, tenure, educational level), bridging differences is essential to reach a common ground (Homan et al., 2008). Not sharing all of the information with the other group members or implying a certain knowledge that not everyone in the group shares can lead to communication failures, as highlighted by meta-analytic findings (Mesmer-Magnus and DeChurch, 2009).

Communication between subgroups and integration of different perspectives is important in any type of group (see Carton and Cummings, 2012 for examples in different contexts). In small groups, research has concentrated on diversity faultlines as hypothetical dividing lines that separate a group into more or less homogeneous subgroups (Lau and Murnighan, 1998; Meyer and Glenz, 2013). They represent a multidimensional measure of team diversity that helps to understand subgroup dynamics in a team. Instead of observing dimensions of diversity such as education level and tenure separately, faultlines consider differences on multiple attributes simultaneously and take the alignment (i.e., the distribution of attributes in a way that homogeneous subgroups form) of these attributes into account (e.g., Lau and Murnighan, 1998; Bezrukova et al., 2007; Carton and Cummings, 2012). A strong faultline implies the formation of subgroups that are homogeneous regarding all attributes under study (for example, a team with a subgroup of blue-collar workers with many years of work experience vs. a subgroup of whitecollar workers that graduated recently). The resulting subgroup formation in turn impacts how communication between team members of the same as well as of different subgroups takes place (Harrison et al., 2002).

Given that the exchange and integration of ideas, perspectives and knowledge is seen as a crucial factor in group success (e.g., Mesmer-Magnus and DeChurch, 2009), tools to assess those communication processes between functional subgroups gain importance when studying small group communication. Most research on communication in diverse groups focuses on communication within the group as a whole, neglecting processes between subgroups (van der Kamp et al., 2011; Jiang et al., 2012; Vora and Markóczy, 2012). When addressing communication specifically between subgroups, researchers mostly focus on selfreported connections between group members. While these self-reports are important to understand the perceptions of group members, objective behavioral data is important to gain additional insights into actual (sub)group dynamics (Meyer et al., 2014; Kolbe and Boos, 2019). Additionally, several challenges, for example the comparability across different groups or varying subgroup sizes, accompany the study and assessment of intersubgroup communication (Straube and Kauffeld, 2020).

With the present study, we aim at addressing the following three points: Firstly, we evaluate measures of intersubgroup communication and introduce the faultine communication index (FCI, Straube and Kauffeld, 2020), a measure based on methods from social network research. Secondly, we aim at combining this approach with interaction analysis using the act4teams coding scheme. By this, we integrate specific communication behaviors into analyses of intersubgroup interaction to provide a more complete understanding of what happens in communication between functional subgroups. Thirdly, we explore how intersubgroup communication can shape meeting outcomes in a sample of 29 organizational groups. We extend the literature on faultline-based subgroups and communication by relating functional faultline strength to between-subgroup communication and thus examine the theoretical foundation of inter-subgroup biases in actual team interaction.

\section{Assessing Communication Patterns in Small Groups}

When examining communication patterns within small groups, social network analysis provides important foundations to understand connections between group members. It focuses on relationships between individuals denominated as ties (Borgatti et al., 2009). These ties can be used to picture the flow of information between team members or serve as proxies for social support or advice (Cross and Parker, 2004). Often, selfreported connections or ties between team members are used as a proxy for proximity, friendship, and also communication between team members (e.g., Ren et al., 2015). To gain a deeper insight into actual behavioral processes taking place during communication or coordination between pairs of team members or within the whole team, several studies have employed aspects of observed communication behavior to depict communication networks, such as safety communication, use of emails, or verbal expressions (e.g., Miller et al., 2010; Alsamadani et al., 2013; Gloor et al., 2017). Sauer and Kauffeld (2013) proposed a way to assess communication within team discussions through network ties based on speaking turns. A tie between two team members is defined as an utterance of one member following an utterance of another member. With this method, it is possible to gain insights into the interaction structure of small group meetings.

So far, scholars studying the impact of faultlines on group interaction have mainly focused on interactions within the group as a whole, grounding on the argument that increased communication within the group accentuates the differences between group members (Hogg and Terry, 2000; van der Kamp et al., 2011). For example, Vora and Markóczy (2012) used the average of the communication frequency (i.e., the communication ties) between each of the group members to assess communication within the group. Other researchers have focused on an overall perception of communication of each group member to the rest of the group (van der Kamp et al., 2011; Jiang et al., 2012). 
Common to these studies and approaches is that they all consider communication processes within the group as a whole. However, theorizing suggests that faultines especially impact the processes between smaller subgroups within a team (Carton and Cummings, 2013). Thus, key to understanding processes in groups affected by faultlines are the dynamics that take place between the more or less homogeneous subgroups created by the faultline.

\section{Subgroup Analyses-Methods, Pitfalls, and a (Possible) Solution}

When turning to interactions between different subgroups, research on analyses of communication between subgroups is scarce (Lau and Murnighan, 2005; Ren et al., 2015; Adair et al., 2017). Most scholars apply methods also used to assess interactions within the whole group.

Lau and Murnighan (2005) used a questionnaire to assess group members' contacts to all other members. They assessed the frequency of communication via email, telephone, and faceto-face in five categories, ranging from less than once a week to more than 16 contacts per week. They averaged the number of a group members' contacts with members from other subgroups. The overall amount of contacts was not taken into account. However, the shared environment of a specific team (e.g., the same work context, shared experiences within the team) always influences individual perceptions and behavior (Kozlowski, 2012). Consequently, the amount and nature of intersubgroup communication will be influenced by the amount and nature of communication that is shared within the whole group.

Also, when we want to depict processes between subgroups, we want to evaluate whether those processes deviate from what would be expected within a given team. Ren et al. (2015) proposed a measure of friendship and animosity ties between members of different subgroups. They calculated the ties between subgroups as the cross-subgroup density (Borgatti et al., 1992), dividing the existing ties between subgroups by the number of all possible ties between subgroups. By this, they took into account that groups with different subgroup constellations have varying possibilities of communicating between subgroups (e.g., a group of six members falling into two subgroups of three with a total of nine possible ties between subgroups vs. falling into one subgroup of four and one subgroup of two with a total of eight possible ties between subgroups).

Ren et al.'s approach is very useful when considering ties between group members of equally large groups with varying subgroup constellations. However, research practice shows that especially in the study of real-world groups, factors such as group size and subgroup constellations are not controllable, compared to experiments. Thus, when we want to capture a more nuanced picture of the group communication at hand, and compare groups with varying amounts of members, researchers face the challenge to compare group processes, such as communication, across groups different in size, and in constellation. When choosing previous approaches (e.g., Ren et al., 2015) that relate intersubgroup communication to possible ties between members, but not to the overall group size, the comparison between different groups is difficult. Figure 1 illustrates this with different groups of different sizes and subgroup constellations, separated by a strong faultline. In group $\mathrm{A}$ and $\mathrm{B}$, there are five members each. In group $\mathrm{C}$, there are four members. In group $\mathrm{A}$, one subgroup of three and one subgroup of two members form. In group $B$, there is one subgroup of four members and one member forming a solo-split. Consequently, there are less possible connections between members of different subgroups than in group A (four compared to six), while the total number of possible ties within the teams is equal. In group $C$, there are two subgroups of two members with a total of four possible connections between subgroups. While the possible ties between subgroups are equal in teams $\mathrm{B}$ and $\mathrm{C}$, there are more possible ties within the whole team in group B than in group C. This means that intersubgroup interactions are more likely in group $C$ than in group B, because there are less possibilities of intrasubgroup interactions. Relating the intersubgroup ties to only the possible ties between the subgroups would result in a biased comparison.

Taken together, researchers need to consider multiple challenges when working with data on groups and subgroups. Table 1 summarizes those challenges as well as solutions to these challenges.

To overcome the challenges that accompany approaches used in the past, the FCI (Straube and Kauffeld, 2020) has recently been introduced. In a first step, communication between subgroups can be related to overall team communication, assessed for example through the number and strength of ties between members. This is done by dividing communication between subgroups by team communication (see the Methods section). Next, the number of possible ties in a group, which is dependent upon the group size, is divided by the number of possible ties between subgroups, which is a function of the constellation of subgroups (see Figure 1). The two resulting scores are multiplied to calculate the FCI, that relates the actual team communication to the possible ties within the given team. Our methods section gives a detailed description of all steps taken to calculate the FCI including formulas. This procedure presents several advantages for the study of small groups. Firstly, it relates the communication between subgroups to communication within the whole group, taking into account that larger groups offer more communication possibilities for group members than smaller groups. Secondly, the possible connections between all group members as well as between the subgroup members can be taken into account (see Figure 1) when studying groups that vary in size or in their subgroup constellations. Thirdly, it is applicable to both perceived connections between a set of group members (selfor externally reported data) as well as observed connections between a set of group members (behavioral data). Lastly, the FCI can be enriched by behavioral data, such as coded interactions between group members, to further explore specific communication behaviors.

\section{How Do They React? Integrating Specific Communication Behaviors Into Intersubgroup Communication Analysis}

In addition to the quantity of communication between subgroups compared to the overall team communication, studying specific communication behaviors, such as finding solutions to problems, structuring a discussion, making plans or disagreeing with 


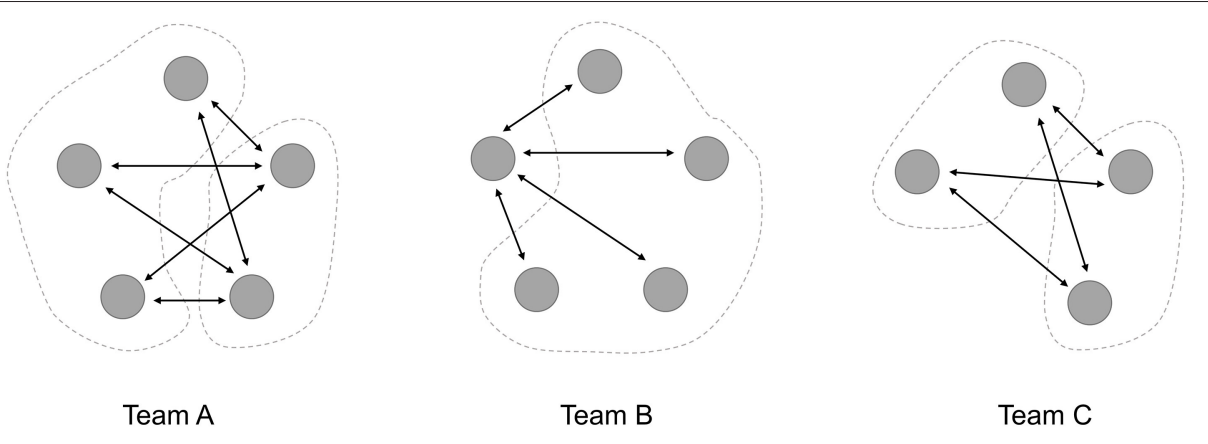

FIGURE 1 | Possibilities of intersubgroup interactions in three exemplary groups. Gray circles represent team members. Dashed lines mark the subgroups in each team. Arrows represent the possible ties between members of different subgroups.

TABLE 1 | Challenges of subgroup analyses and proposed solutions.

\begin{tabular}{ll}
\hline Challenges & Proposed solutions \\
\hline $\begin{array}{l}\text { Challenge 1: subgroups are } \\
\text { nested in groups, and thus } \\
\text { influenced by amount of group }\end{array}$ & $\begin{array}{l}\text { Relate intersubgroup communication } \\
\text { to team communication }\end{array}$ \\
$\begin{array}{l}\text { communication } \\
\text { Challenge 2: varying group size }\end{array}$ & $\begin{array}{l}\text { Include possible ties between all team } \\
\text { between teams making }\end{array}$ \\
$\begin{array}{l}\text { comparisons biased } \\
\text { Challenge 3: different subgroup } \\
\text { constellations (i.e., 3:3 vs. 2:4) in }\end{array}$ & $\begin{array}{l}\text { Include possible ties between } \\
\text { equally large teams }\end{array}$ \\
$\begin{array}{l}\text { Challenge 4: self-reports of } \\
\text { interaction frequency or tie }\end{array}$ & $\begin{array}{l}\text { Choose a behavioral approach } \\
\text { strength can be biased }\end{array}$ \\
\hline
\end{tabular}

other group members, is extremely relevant to understand communication dynamics in groups (Sunwolf and Frey, 2005; Kauffeld and Lehmann-Willenbrock, 2012; Meinecke and Lehmann-Willenbrock, 2015). While functional communication (i.e., behaviors contributing to advance problem solving and information sharing, aiming to structure a discussion, and fostering a positive climate within the group; Kauffeld et al., 2018) between subgroups offers the possibility to establish positive contact between in- and outgroup and thus diminish the negative effect of social categorization (Pettigrew, 1998), dysfunctional communication (i.e., behaviors directed at criticizing others or complaining; Kauffeld et al., 2018) between subgroups can raise potential for misunderstandings and conflict (Vora and Markóczy, 2012). First results connecting communication networks to functional and dysfunctional behaviors show that functional and dysfunctional meeting networks differ in their structure, underlining the relevance of specific communication behaviors for communication dynamics (Sauer and Kauffeld, 2016).

We propose to combine the calculation of the FCI with the act4teams coding scheme (Kauffeld and Lehmann-Willenbrock, 2012; Kauffeld et al., 2018). The act4teams coding scheme is a coding scheme with mutually exclusive and exhaustive observation categories in which utterances can be classified into one of 44 behavioral codes. These codes are divided into four broader categories: problem-focused behaviors, procedural behaviors (positive and negative), socioemotional behaviors (positive and negative), and action-oriented behaviors (proactive and counteractive). This allows the comparison of positive and negative statements within and between subgroups as well as the comparison of different behavioral categories (see section Meeting Interaction for a detailed description of the coding scheme in this context).

\section{Applying the Analysis of Intersubgroup Communication to Organizational Team Meetings}

Besides the methodological extension, a further goal of this study is to show the FCI in application to real-life teams and to develop hypotheses on this. In this context, we shed light on the role of intersubgroup communication in mediating the effects of functional faultline strength on team outcomes in organizational meetings.

Meetings present an opportunity for groups to reflect on their work, discuss problems and goals, and find solutions to everyday work issues (Rogelberg et al., 2006). In organizational meetings, effective communication is the key to success (Kauffeld and Lehmann-Willenbrock, 2012). Designing effective meetings as well as ensuring that measures discussed are taken into action after a meeting are central interests of team managers and organizations (e.g., Scott et al., 2012; Lehmann-Willenbrock et al., 2018). Shifting focus to the way in which team members exchange information within a meeting can lay ground for a deeper understanding of team communication processes and their role in the relationship between team compositional factors and team outcomes.

In this study, we focus on functional faultlines and resulting subgroup formation as they are likely to bring different perspectives and knowledge to a group (e.g., Cronin and Weingart, 2007; Jehn and Rupert, 2008; Polzer and Kwan, 2012). Certain attributes might determine the access to information, for example functional background or the number of years a team member has spent in the organization (Mayo et al., 2017). Integrating these perspectives is crucial for group success 
and a challenge to researchers and team managers alike, since a common understanding is needed for a successful integration (Huber and Lewis, 2010). Figure 2 shows our proposed research model.

\section{The Impact of Functional Faultlines on Group Interaction}

Drawing on the categorization elaboration model (CEM, van Knippenberg et al., 2004), positive effects of different perspectives and broader knowledge within a team can only unfold when team members elaborate on information thoroughly. However, social categorization processes can hinder information elaboration and thus performance. This is especially likely when certain conditions are met. When the comparative fit between individuals of different subgroups is high, meaning that the similarities between members of the same subgroup as well as the differences to members of a different subgroup are more obvious, social categorization becomes more likely. By definition, this is the case when the faultline is strong, leading to homogeneous subgroups regarding multiple member attributes (Williams and O'Reilly, 1998). Further, a high cognitive accessibility, i.e., the ease with which members can be classified into certain social categories, increases the likelihood for social categorization. The cognitive accessibility is especially high for visible attributes (Fiske, 2000), but can also be triggered by contextual primes (i.e., tenure will be more easily accessible in situations where the group discusses problems that can be solved with information regarding the firm's history). Lastly, social categorization becomes more likely when the differences are meaningful to an individual, resulting in high normative fit. This is the case when the attributes considered are relevant to the task at hand (van Knippenberg et al., 2007).

This indicates that categorizing oneself and other members into different social categories (which can be different functional subgroups, e.g., Bezrukova et al., 2012) fosters a separation of the subgroups and thus hinders information exchange. In line with the findings on ingroup preference (e.g., Williams and O'Reilly, 1998; van Knippenberg and Schippers, 2007), research shows that especially between heterogeneous members, information exchange is less likely and, when information is exchanged, group members are more likely to exchange information that is common to everyone instead of focusing on unique knowledge (Stasser and Titus, 1985; Mesmer-Magnus and DeChurch, 2009). So far, several studies have focused on team information exchange in the context of faultlines. Groups with a strong educational faultline (based on educational specialty, age, gender, and educational level) have been shown to share less task-relevant information within the whole group than groups with a weak educational faultline (Jiang et al., 2012). Further, information elaboration has been shown to mediate the link between faultline strength and task performance (Meyer and Schermuly, 2012). Additionally, when functional faultlines are strong, subgroups within a team will likely develop separate mental models which are difficult to integrate as well as their own representation of how a task should be conducted and how problems should be solved (Carton and Cummings, 2012). Most of the time, these strategies are implicit and adhering to them could lead to misunderstandings and overall performance inhibitions (Rico et al., 2008). Functional subgroups arising from strong faultlines tend to be highly specialized, as knowledge is mostly integrated within subgroups (Qu and Liu, 2017). This can lead to inconsistent definitions of the team's problems across subgroups, inhibiting information exchange within the team as a whole (Cronin and Weingart, 2007). Understanding how these processes translate into actual behavior in organizational meetings could deliver starting points for designing effective meetings. What remains to be explored is how these information exchange processes between different functional subgroups unfold within a meeting. Given the specific structure of teams affected by faultlines, we propose that:

H1: In groups with strong functional faultlines, information exchange between subgroups is impaired more strongly than in groups with weak functional faultlines.

\section{Intersubgroup Information Exchange and Action Planning in Meetings}

As a substantial number of meetings is ineffective and even described as a "waste of time" (Rogelberg et al., 2006), scholars have focused on factors for successful meetings (e.g., Scott et al., 2012; Reiter-Palmon and Sands, 2015; Lehmann-Willenbrock et al., 2018). In this regard, research has shown that the way in

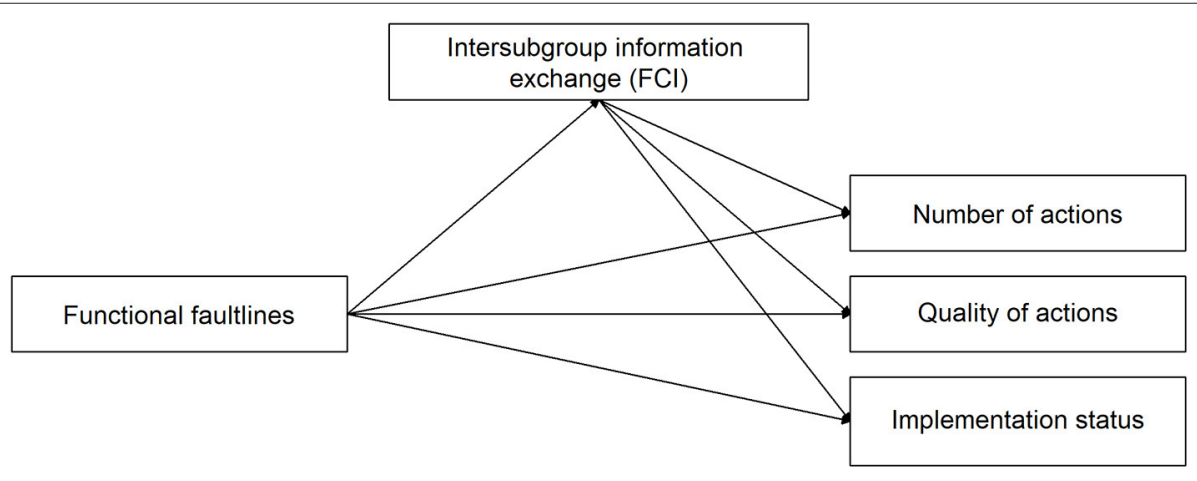

FIGURE 2 | Proposed research model. 
which a group communicates within a meeting is central to their success (e.g., Kauffeld and Lehmann-Willenbrock, 2012; Sauer and Kauffeld, 2013).

We argue that effective information exchange is relevant to action planning, that is the development of measures to be taken into action after a meeting, for two reasons: First, elaborating all task relevant information ensures that all available information is taken into account, an important factor in successful collective decision making (e.g., van Ginkel and van Knippenberg, 2008). Second, a common ground is needed for all team members to share an understanding of what the actions that have to be taken include (e.g., Carton and Cummings, 2012). Only then, they are able to work toward implementing these actions.

Research as shown that solutions only foster productivity when they are not only discussed but also implemented later on (Kauffeld, 2006; Lehmann-Willenbrock et al., 2018). To ensure that measures planned in a meeting are also taken into action later on, communicating effectively within a meeting is crucial (Lehmann-Willenbrock et al., 2013). This includes effectively elaborating all task relevant information to develop a shared understanding of goals and actions discussed in a meeting, for example by cross-linking problems and solutions (e.g., Mesmer-Magnus and DeChurch, 2009; Kauffeld and Lehmann-Willenbrock, 2012). This is especially crucial between faultline based subgroups, as they tend to dispose of a broad range of knowledge and expertise. Bringing together these different "thought worlds" (Dougherty, 1992) can enhance team performance and the successful implementation of actions, as all available information needs to be discussed (LehmannWillenbrock et al., 2013). On the other hand, not sharing and elaborating on all information between subgroups can lead to different ideas of the desired outcome and thus hinder the quality of action planning after a meeting. We therefore state:

$\mathrm{H} 2$ : Information exchange between subgroups is positively related to the quality of action planning after a meeting.

Integrating our first two hypotheses and following theorizing on diversity and faultlines in meetings (Gerpott and LehmannWillenbrock, 2015; Straube and Kauffeld, 2020), meeting behavior can act as a mediator between faultine strength and group outcomes. Negative effects of faultlines on team outcomes, such as difficulties in developing a common understanding (Carton and Cummings, 2012), might unfold through interactional processes within a group (Meyer et al., 2014). We propose intersubgroup information exchange as a central group process to transmit the effects of faultlines into outcomes:

H3: Information exchange between subgroups mediates the negative effects between faultlines and quality of action planning after a meeting.

\section{METHODS}

\section{Participants and Procedure}

The data was a subset of a large longitudinal investigation on team interactions and the effectiveness of teamwork. In the present study, a total of 36 work groups $(N=205$ employees $)$ from the production departments of two medium-sized German companies were examined. These groups represent the total of available team meetings of the last measurement point of the large investigation. We only chose one measurement point to ensure that there was only one meeting per group in the study. There were 18 groups from an electrical company and 18 groups from an automotive supply company. Due to missing information on functional background and organizational tenure from eight individuals in seven teams, not all team members could be allocated to their respective subgroups. Therefore, seven teams had to be excluded, resulting in a final sample of 29 teams $(N=$ 161 employees). Three to seven coworkers participated in each meeting. Eighty-five percent of the group members were male, which is representative of the companies involved. Employees' ages ranged from 17 to 57 years with a mean of 35 years. Approximately $74 \%$ had completed technical training, about $12 \%$ were untrained workers, and about $1 \%$ had completed technical college. Thirteen percent of the participants indicated other training. Organizational tenure varied between 1 month and 39 years with a mean of 10 years. All teams were self-managed. As part of the large longitudinal investigation, all groups participated in an intervention to improve meetings which took place several weeks before the meetings examined in the present study.

The groups discussed a problem-solving task relevant to their specific work activities, which they chose themselves (e.g., How can the quality of our work be improved?). Participants confirmed that this type of task was a regular topic of their meetings and that it was important to work on that specific task. This guaranteed that the discussion outcomes were relevant to the groups and occurred within their natural work environment.

\section{Functional Faultlines}

Functional faultlines were calculated using the average silhouette width (ASW) method (Meyer and Glenz, 2013). The calculations were performed in $\mathrm{R}$ with the asw.cluster package for faultline calculation (Meyer and Glenz, 2013). Faultline strength ranges from 0 to 1 , with 0 representing the minimum separation of a group into homogeneous subgroups. A value of 1 represents perfect alignment of attributes, resulting in maximum separation of a group into homogeneous subgroups. We integrated the most commonly used attributes for functional faultlines, educational level, and organizational tenure, into our measurement (Thatcher and Patel, 2012).

\section{Meeting Interaction}

For analysis of the videotaped interaction data, we used the act4teams coding scheme (e.g., Kauffeld, 2006; Kauffeld and Lehmann-Willenbrock, 2012; Meinecke and LehmannWillenbrock, 2015; Kauffeld et al., 2018). Utterances were unitized by sense units and subsequently coded by five trained, independent coders using Interact software (Mangold, 2010). During the coding process, each unit was assigned to one of the 44 exclusive categories of act4teams. In order to determine the quality of the coding, a subset of the videos was double coded, i.e., coded by two of the coders, to subsequently determine 
the interrater reliability between all pairs of coders. The interrater reliability was excellent (Fleiss' $\kappa=0.81)^{1}$. We focused on problem-focused statements to represent information exchange and integration between group members. In the act4teams coding scheme, problem-focused communication consists of the subcodes differentiating a problem, cross-linking a problem, differentiating a solution, contributing a solution, or describing a solution, cross-linking a solution, and statements about the organization or about knowledge management. For further analyses, the absolute number of utterances coded in each observational category was enumerated per group member.

\section{Faultline Communication Index (FCl) Determining Intersubgroup Interaction}

To determine interaction between subgroups, we turned to a method proposed by Sauer and Kauffeld (2013). They proposed a way to assess communication within team meetings as network ties. A tie between two team members is defined as a speaking turn, that is a team member's utterance following an utterance of another team member. These ties are then summed up for each communication pair (a pair of two team members). We counted all problem-focused speaking-turns (i.e., one group member makes a problem-focused utterance after another group member has spoken) for each team member and displayed the values in a "who-to-whom" matrix (see Table 2 for an example). Column cells represent the number of problem-focused utterances each speaker gave in reaction to utterances from all other team members (i.e., team member A reacted 39 times with a problemfocused utterance to any utterance from team member $C$ and 10 times with a problem-focused utterance to any utterance from team member $\mathrm{D}$, and so on) while row cells represent the number of utterances a speaker directed to each other team member, however, our analysis only took those utterances into account that were followed by a problem-focused statement (i.e., team member A talked 26 times before team member B made a problem-focused utterance and 21 times before team member $\mathrm{C}$ made a problem-focused utterance, and so on). The member-tosubgroup attribution was obtained via the ASW-package in R.

\section{Calculating the FCl for Between Subgroup Information Exchange}

To calculate the FCI as a measure of between-subgroup information exchange, we employed the formulas proposed by Straube and Kauffeld (2020). Firstly, all problem-focused speaking turns between members of two different subgroups were added. This sum was then divided by the total amount of problem-focused speaking turns between all team members following this formula:

speaking turn ratio $=\frac{\text { number of speaking turns betw. subgroups }}{\text { overall speaking turns }}$

For the exemplary team displayed in Table 2, the speaking turn ratio was $201 / 306=0.66$. To account for differences in group size and subgroup constellation, we further calculated the possible

${ }^{1}$ Please note that the coding process was part of the larger study with meetings at several measurement points. ties within a team (overall ties) as well as the possible ties between subgroups:

$$
\text { possible overall ties }=\frac{N(N-1)}{2}
$$

$$
\begin{aligned}
\text { possible ties between subgroups }= & N_{\text {subgroup A }} * N_{\text {subgroup B }} \text { (3) } \\
& +N_{\text {subgroup A }} * N_{\text {subgroup C }} \\
& +N_{\text {subgroup B }} * N_{\text {subgroup C }}
\end{aligned}
$$

In the exemplary team, possible ties between the six team members were 15 and possible ties between subgroups were 2 * $4=8$. Equations (2) and (3) were then divided to result in the so-called tie ratio, representing the ratio of possible ties within a team (overall ties) to possible ties between subgroups. This tie ratio ensures that the value of the final FCI (see Equation 5) is not biased by team size or subgroup sizes (see Straube and Kauffeld, 2020, for a development of the measure).

$$
\text { tie ratio }=\frac{\text { possible overall ties }}{\text { possible ties betw. subgroups }}
$$

The tie ratio for the exemplary team from Table 2 was 15/8 $=1.88$. The final score of intersubgroup information exchange represents problem-focused communication between subgroups controlled for overall problem-focused communication, team and subgroup size as well as subgroup constellation:

Faultine Communication Index $(F C I)=$ speaking turn ratio $*$ tie ratio

The FCI of the exemplary team was $0.66 * 1.88=1.24$. The FCI reaches a value of 1 when communication between and within subgroups is perfectly balanced. A score below 1 indicates that less communication takes place between subgroups than within subgroups. A score above 1 indicates more communication between subgroups than within subgroups (Straube and Kauffeld, 2020).

\section{Quality of the Action Planning}

To evaluate the quality of action planning, we employed three separate measures which were then used as separate outcomes in our multivariate path model. After the meeting, the groups listed all measures that they wanted to take after their meeting in an action plan (e.g., report damages on machines, implement software trainings for workers, change material of a product to avoid defects). We employed one quantitative and two qualitative (self- and external rating) ratings to evaluate the quality of the action plan.

Firstly, we counted the number of actions. The amount of measures in the action plan were enumerated per group. In our sample, the number of measures ranged from 0 to 15 .

Secondly, the quality of the measures was rated by the expert coders that analyzed the videotapes. Quality ratings ranged from 0 -the measure was not mentioned during the meeting to $1-\mathrm{a}$ complete action plan has been made for the respective measure during the meeting. Ratings were made on a six-point scale in 
TABLE 2 | Example of a "who-to-whom" matrix for problem-focused communication between subgroups.

\begin{tabular}{|c|c|c|c|c|c|c|c|}
\hline & $\begin{array}{c}\text { Team } \\
\text { member A } \\
\text { PF (1) }\end{array}$ & $\begin{array}{c}\text { Team } \\
\text { member B } \\
\text { PF (1) }\end{array}$ & $\begin{array}{c}\text { Team } \\
\text { member C } \\
\text { PF (2) }\end{array}$ & $\begin{array}{c}\text { Team } \\
\text { member D } \\
\text { PF (2) }\end{array}$ & $\begin{array}{c}\text { Team } \\
\text { member E } \\
\text { PF (2) }\end{array}$ & $\begin{array}{c}\text { Team } \\
\text { member F } \\
\text { PF (2) }\end{array}$ & Sum \\
\hline Team member A (1) & 0 & 26 & 21 & 10 & 19 & 5 & 81 \\
\hline Team member B (1) & 39 & 0 & 7 & 10 & 6 & 2 & 64 \\
\hline Team member C (2) & 39 & 13 & 0 & 6 & 12 & 2 & 72 \\
\hline Team member D (2) & 10 & 15 & 4 & 0 & 4 & 1 & 34 \\
\hline Team member E (2) & 20 & 18 & 4 & 5 & 0 & 0 & 47 \\
\hline Team member $F(2)$ & 5 & 1 & 1 & 1 & 0 & 0 & 8 \\
\hline Sum & 113 & 73 & 37 & 32 & 41 & 10 & 306 \\
\hline
\end{tabular}

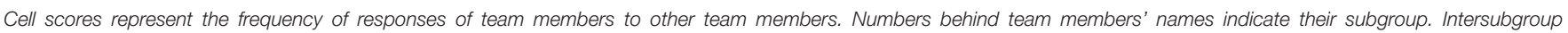
communication is marked in gray. $P F=$ problem-focused statements.

steps of 0.2. For each group, a mean rating was obtained, ranging from 0 to 1 in our sample.

Thirdly, we considered the implementation status. Six to eight weeks after the meeting, the groups indicated the status of the measures that were to be taken after the meeting with the following scale: (0) The measure has not been taken yet, (1) the implementation is in progress, or (2) the measure is implemented. We obtained a mean score for the implementation status of each group, ranging from 0 to 2 in the present sample.

\section{Controls $^{2}$}

To be able to compare the FCI to previously employed measures to assess interactions between subgroups described before, we calculated the average cross-subgroup contacts as applied by Lau and Murnighan (2005) as well as the cross-subgroup density as applied by Ren et al. (2015). The cross-subgroup contacts were calculated as the number of problem-focused speaking turns between members of different subgroups, divided by team size. The cross-subgroup density (Borgatti et al., 1992) was calculated as problem-focused speaking turns between subgroups divided by possible ties between subgroups. We chose the problemfocused ties/contacts to ensure comparability with the FCI.

We controlled for education level diversity and tenure diversity in our analyses to evaluate the effects of faultlines strength given a team's diversity. For education level diversity, we employed the Blau Index of heterogeneity (Blau, 1977). Tenure diversity was calculated using the team-based standard deviation.

\section{DATA ANALYSIS}

We conducted path analysis with indirect effects in MPlus Version 8 (Muthén and Muthén, 2017) with 1,000 bootstrap samples. We included functional faultline strength as the predictor variable, information exchange between subgroups (FCI) as the mediating variable and quality of action plan, including number of actions, quality of actions and

\footnotetext{
${ }^{2}$ As noted by a recent publication (Certo et al., 2020), the use of ratios in research, as is the case in calculating the FCI, can impact the interpretability of statistical models. If sample size allows, we thus advise scholars implementing the FCI into their research to include the lower order terms (number of speaking turns between subgroups, overall speaking turns, possible overall ties, possible ties between subgroups) into their models to control for confounding effects.
}

implementation status, as outcome variables. Education and tenure diversity were inserted as control variables.

\section{RESULTS}

Means, standard deviations, and intercorrelations for all study variables are presented in Table 3. Functional faultline strength ranged from 0.24 to 1.00 , indicating that all teams were affected by faultlines to some extent. On average, teams had 418.34 talk-turns in their meetings ( $S D=211.37)$. The mean number of problem-focused talk-turns, i.e., information exchange and integration, in teams was $163.76(S D=81.30)$. The FCI, representing intersubgroup information exchange, ranged from 0.40 to 2.21 with a mean of 1.03 and a standard deviation of 0.34 , showing that while on average, information exchange was balanced within and between subgroups, there was variation between teams regarding the distribution of information exchange.

Table 3 further shows descriptive statistics and intercorrelations of the average cross-subgroup contacts as well as the cross-subgroup density. Both variables show moderate to strong correlations with the FCI. As opposed to the FCI, both cross-subgroup contacts as well as cross-subgroup density showed strong correlations with the overall speaking turns. In other words, the more speaking turns in a team, the higher the values for both variables. The FCI was not related to overall speaking turns. Further, cross-subgroup density showed a marginally significant negative correlation with possible overall ties, while cross-subgroup contacts showed a marginally significant positive relationship with possible ties between subgroups. We see a correlation of all three variables to the number of measures, while only the FCI is related to the quality of measures (expert rating).

Table 4 shows the results of the path analysis. The model had five degrees of freedom and showed acceptable to moderate fit to the data [root mean squared error of approximation (RMSEA) $=0.077$, comparative fit index $(\mathrm{CFI})=0.923$, standardized root mean squared residual $(\mathrm{SRMR})=0.086]$.

Functional faultline strength did not impact the FCI $(B=$ $-0.010, p=0.98)$. In other words, strong functional faultlines did not hinder (nor foster) information exchange between the 
TABLE 3 | Descriptive statistics and correlations among study variables.

\begin{tabular}{|c|c|c|c|c|c|c|c|c|c|c|c|c|c|c|c|c|c|c|c|c|}
\hline & $M$ & $S D$ & Min & Max & (1) & (2) & (3) & (4) & (5) & (6) & (7) & (8) & (9) & (10) & (11) & (12) & (13) & (14) & (15) & (16) \\
\hline $\begin{array}{l}\text { 1. Functional faultline strength } \\
\text { (ASW) }\end{array}$ & 0.62 & 0.16 & 0.24 & 1.00 & - & 0.054 & -0.164 & -0.115 & 0.195 & $-0.603^{\star \star}$ & 0.092 & 0.219 & 0.249 & 0.072 & 0.043 & 0.054 & 0.042 & 0.032 & 0.238 & 0.120 \\
\hline $\begin{array}{l}\text { 2. Intersubgroup information } \\
\text { exchange (FCl) }\end{array}$ & 1.03 & 0.34 & 0.40 & 2.21 & 0.054 & - & $0.415^{*}$ & -0.057 & $460^{*}$ & -0.122 & -0.305 & $0.374^{\star}$ & 0.175 & 0.197 & 0.004 & 0.182 & -0.026 & 0.304 & $0.381^{*}$ & $0.520^{* \star}$ \\
\hline $\begin{array}{l}\text { 3. Quality of measures (expert } \\
\text { rating) }\end{array}$ & 0.79 & 0.26 & 0.00 & 1.00 & -0.164 & $0.415^{*}$ & - & $0.369^{\dagger}$ & 0.253 & 0.225 & 0.047 & 0.084 & -0.186 & 0.225 & 0.198 & 0.261 & 0.074 & 0.082 & -0.022 & -0.078 \\
\hline 4. Implementation status & 1.61 & 0.56 & 0.00 & 2.00 & -0.115 & -0.057 & $0.369^{\dagger}$ & - & 0.195 & $0.350^{\dagger}$ & -0.041 & $0.354^{\dagger}$ & 0.156 & 0.070 & $0.431^{*}$ & 0.198 & $0.325^{t}$ & $-0.464^{\star}$ & 0.270 & -0.033 \\
\hline 5. Number of measures & 4.86 & 3.80 & 0.00 & 15.00 & 0.195 & $0.460^{*}$ & 0.253 & 0.195 & - & 0.019 & 0.106 & $0.594^{\star \star}$ & * $0.550^{\star \star}$ & 0.257 & 0.174 & 0.262 & -0.117 & 0.156 & $0.508^{\star \star}$ & $0.417^{\star}$ \\
\hline 6. Education level diversity & 0.24 & 0.20 & 0.00 & 0.64 & $-0.603^{\star \star}$ & -0.122 & 0.225 & $0.350^{\dagger}$ & 0.019 & - & -0.115 & 0.014 & -0.072 & 0.050 & 0.115 & 0.185 & 0.063 & -0.049 & -0.069 & -0.116 \\
\hline 7. Tenure diversity & 6.66 & 3.68 & 0.55 & 15.54 & 0.092 & -0.305 & 0.047 & -0.041 & 0.106 & -0.115 & - & -0.253 & -0.190 & 0.056 & -0.016 & -0.032 & -0.232 & 0.090 & $-0.317^{\dagger}$ & $-0.397^{\star}$ \\
\hline $\begin{array}{l}\text { 8. Speaking turns btw. } \\
\text { subgroups (pf) }\end{array}$ & 101.45 & 59.42 & 12 & 207 & 0.219 & $0.374^{*}$ & 0.084 & $0.354^{\dagger}$ & $0.594^{* *}$ & 0.014 & -0.253 & - & $0.892^{\star \star}$ & $0.454^{*}$ & $0.595^{\star \star}$ & $0.511^{* \star}$ & $* 0.352^{\dagger}$ & -0.080 & $0.923^{\star \star}$ & * $0.509^{* \star}$ \\
\hline 9. Overall speaking turns (pf) & 163.76 & 81.30 & 38 & 342 & 0.249 & 0.175 & -0.186 & 0.156 & $0.550^{\star *}$ & -0.072 & -0.190 & $0.892^{\star \star}$ & - & $0.423^{*}$ & $0.421^{*}$ & $0.462^{\star}$ & 0.110 & 0.124 & $0.819^{\star *}$ & * $0.495^{\star \star}$ \\
\hline 10. Possible overall ties & 13.07 & 5.55 & 3.00 & 21.00 & 0.072 & 0.197 & 0.225 & 0.070 & 0.257 & 0.050 & 0.056 & $0.454^{*}$ & $0.423^{*}$ & - & $0.791^{\star \star}$ & $0.945^{\star \star}$ & * $0.423^{\star}$ & $0.523^{\star \star}$ & 0.134 & $-0.330^{\dagger}$ \\
\hline $\begin{array}{l}\text { 11. Possible ties btw. } \\
\text { subgroups }\end{array}$ & 7.72 & 4.11 & 2.00 & 17.00 & 0.043 & 0.004 & 0.198 & $0.431^{*}$ & 0.174 & 0.115 & -0.016 & $0.595^{\star \star}$ & $0.421^{*}$ & $0.791^{\star *}$ & - & $0.779^{\star \star}$ & * $0.776^{\star \star}$ & -0.103 & $0.330^{t}$ & -0.309 \\
\hline 12. Team size & 5.45 & 1.21 & 3.00 & 7.00 & 0.054 & 0.182 & 0.261 & 0.198 & 0.262 & 0.185 & -0.032 & $0.511^{\star \star}$ & $0.462^{*}$ & $0.945^{\star \star}$ & $0.779^{\star \star}$ & - & $0.409^{\star}$ & $0.450^{*}$ & 0.176 & -0.272 \\
\hline 13. Number of subgroups & 2.35 & 0.61 & 2.00 & 4.00 & 0.042 & -0.026 & 0.074 & $0.325^{\dagger}$ & -0.117 & 0.063 & -0.232 & $0.352^{\dagger}$ & 0.110 & $0.423^{*}$ & $0.776^{\star \star}$ & $0.409^{*}$ & - & $-0.409^{\star}$ & 0.213 & -0.282 \\
\hline 14. Mean subgroup size & 2.85 & 0.90 & 1.67 & 5.29 & 0.032 & 0.304 & 0.082 & $-0.464^{*}$ & 0.156 & -0.049 & 0.090 & -0.080 & 0.124 & $0.523^{\star \star}$ & -0.103 & $0.450^{\star}$ & $-0.409^{\star}$ & - & -0.227 & -0.085 \\
\hline $\begin{array}{l}\text { 15. Average cross-subgroup } \\
\text { contacts (pf) }\end{array}$ & 18.28 & 9.06 & 2.00 & 35.40 & 0.238 & $0.381^{*}$ & -0.022 & 0.270 & $0.508^{\star *}$ & -0.069 & $-0.317^{\dagger}$ & $0.923^{* *}$ & $0.819^{\star *}$ & 0.134 & $0.330^{\dagger}$ & 0.176 & 0.213 & -0.227 & - & $0.738^{\star \star}$ \\
\hline $\begin{array}{l}\text { 16. Cross-subgroup density } \\
\text { (pf) }\end{array}$ & 14.31 & 7.40 & 1.33 & 30.67 & 20 & $520^{\star *}$ & * -0.078 & 0.033 & $417^{\star}$ & -0.116 & $-0.397^{\star}$ & $509^{\star \star}$ & $0.495^{\star \star}$ & $-0.330^{\dagger}$ & -0.309 & -0.272 & -0.282 & -0.085 & $0.738^{\star \star}$ & - \\
\hline
\end{tabular}

ASW, average silhouette width; pf, problem-focused statements. $N=29$ teams. For comparability reasons, we display three decimal places.

${ }^{\dagger} p<0.10 .{ }^{*} p<0.05 .{ }^{* *} p<0.01$ (two-tailed). 
TABLE 4 | Model results for the path analysis with mediation.

\begin{tabular}{|c|c|c|c|c|c|c|c|c|c|c|c|c|c|c|}
\hline & \multicolumn{2}{|c|}{$\begin{array}{l}\text { Intersubgroup } \\
\text { information } \\
\text { elaboration }\end{array}$} & \multicolumn{4}{|c|}{ Number of measures } & \multicolumn{4}{|c|}{ Quality of measures (expert rating) } & \multicolumn{4}{|c|}{ Implementation status } \\
\hline & Estimate & SE & \multicolumn{2}{|c|}{ Estimate } & \multicolumn{2}{|c|}{ SE } & \multicolumn{2}{|c|}{ Estimate } & \multicolumn{2}{|c|}{ SE } & \multicolumn{2}{|c|}{ Estimate } & \multicolumn{2}{|c|}{ SE } \\
\hline Intercept & $1.048^{\star \star \star}$ & 0.271 & \multicolumn{2}{|c|}{-7.862} & \multicolumn{2}{|c|}{5.283} & \multicolumn{2}{|c|}{0.122} & \multicolumn{2}{|c|}{0.370} & \multicolumn{2}{|c|}{0.742} & \multicolumn{2}{|c|}{0.901} \\
\hline $\begin{array}{l}\text { Functional faultline } \\
\text { strength (ASW) }\end{array}$ & -0.010 & 0.450 & \multicolumn{2}{|c|}{6.363} & \multicolumn{2}{|c|}{5.457} & \multicolumn{2}{|c|}{0.070} & \multicolumn{2}{|c|}{0.334} & \multicolumn{2}{|c|}{-0.148} & \multicolumn{2}{|c|}{0.916} \\
\hline Tenure diversity & & & \multicolumn{2}{|c|}{0.288} & \multicolumn{2}{|c|}{0.176} & \multicolumn{2}{|c|}{0.020} & \multicolumn{2}{|c|}{0.015} & \multicolumn{2}{|c|}{0.040} & \multicolumn{2}{|c|}{0.032} \\
\hline Educational diversity & & & \multicolumn{2}{|c|}{6.143} & \multicolumn{2}{|c|}{4.947} & \multicolumn{2}{|c|}{$0.463^{\dagger}$} & \multicolumn{2}{|c|}{0.240} & \multicolumn{2}{|c|}{0.823} & \multicolumn{2}{|c|}{0.786} \\
\hline \multirow{2}{*}{$\begin{array}{l}\text { Intersubgroup } \\
\text { information } \\
\text { exchange (FCl) }\end{array}$} & & & \multicolumn{2}{|c|}{$5.084^{*}$} & \multicolumn{2}{|c|}{2.224} & 0.3 & $3^{\star}$ & & & 0.4 & & 0.3 & \\
\hline & & & Effect & SE & LLCl & ULCI & Effect & SE & LLCl & ULCI & Effect & SE & LLCl & ULCI \\
\hline $\begin{array}{l}\text { Indirect effect of } \\
\text { faultline strength }\end{array}$ & & & -0.051 & 2.517 & -3.928 & 3.651 & -0.003 & 0.176 & -0.320 & 0.237 & -0.004 & 0.283 & -0.480 & 0.298 \\
\hline
\end{tabular}

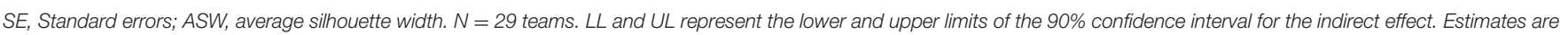
unstandardized. For comparability reasons, we display three decimal places.

${ }^{\dagger} p<0.10,{ }^{\star} p<0.05,{ }^{\star \star} p<0.01,{ }^{\star \star \star} p<0.001$ (two-tailed).

subgroups, refuting $\mathrm{H} 1$. As hypothesized, the FCI positively impacted outcomes regarding action planning. The higher the ratio of information exchange between subgroups (the FCI), the higher the external rating of the quality of the measures $(B=$ 0.343, $p=0.025)$ and the higher the number of actions $(B=$ 5.084, $p=0.022$ ). There was no effect on the implementation status 6 to 8 weeks after the meeting ( $B=0.411, p=0.252)$. In other words, intersubgroup information exchange was linked to more and better measures discussed during the meeting. H2 could partially be accepted. There were no indirect effects of faultline strength on the aspects of quality of the action plan via intersubgroup information exchange ( $I E=-0.051, p=0.984$ for number of actions, $I E=-0.003, p=0.984$ for quality of measures, $I E=-0.004, p=0.988$ for implementation status). $\mathrm{H} 3 \mathrm{had}$ to be refuted.

\section{DISCUSSION}

In this article, we present and extend a novel approach of between subgroup communication, the FCI (Straube and Kauffeld, 2020). This measure presents an opportunity to study communication between subgroups in real life small groups that are likely varying in group size and in subgroup constellations. We further enrich the study of intersubgroup communication by integrating a behavioral process approach into the analyses. This allows a more fine-grained approach to analyzing and understanding communication between subgroups.

Our results demonstrate that the FCI is preferable to the use of cross-subgroup contacts or cross-subgroup density as a measure to intersubgroup information exchange when group constellations vary. Compared to these previously employed measures to capture interactions between subgroups, the FCI showed to be less biased by group makeup (that is, the possible overall ties within a group as well as possible ties between subgroups) and by overall speaking turns within the group.
We show how the FCI can be applied to meeting research by integrating it into a model linking faultline strength to meeting outcomes. We examined how meeting behavior-namely the information exchange between faultline-based subgroups-can mediate the negative effects of faultlines on meeting outcomes. With our study, we wanted to shed light onto "processes that are responsible for translating diversity into action" (Roberge and Van Dick, 2010, p. 298) and to examine whether faultlines come alive in micro-level interactions within team meetings. While we did not find the proposed negative effect of functional faultline strength on information exchange between subgroups, we found interesting results concerning the influence of intersubgroup communication on team outcomes. Information exchange between subgroups showed a positive impact on (a) the number of measures a group recorded after a meeting and (b) whether a measure is discussed thoroughly within a meeting.

\section{Theoretical Implications}

With our study, we contribute to the growing field of subgroups in work teams (Carton and Cummings, 2012). By integrating measures from social network analysis and a behavioral process approach, we extend existing methodology to assess processes taking place between faultline-based subgroups (e.g., Lau and Murnighan, 2005; Ren et al., 2015). As the FCI controls for different team sizes and different subgroup constellations (see Figure 1), it is applicable to datasets from organizational teams that show variations in their group sizes as well as number and size of subgroups. Further, the type of behavior that is shown can easily be integrated into the analyses by using behavioral codes from the act4teams coding scheme or other available coding schemes that fit the respective research questions. This is relevant to unpack the within-team processes that take place when faultlines and subgroups are present (Bonito and Sanders, 2011; Meyer et al., 2014). 
Turning to the results of our empirical investigation, we can take several implications from the application of the FCI to processes in organizational groups. While some studies have carved out positive effects of functional faultlines (e.g., Gibson and Vermeulen, 2003; Bezrukova et al., 2009), faultlines have often been described as a hindering factor for communication in teams in past research (Lau and Murnighan, 2005; Meyer et al., 2011; Vora and Markóczy, 2012). Quite contrary to these results, in our study, information exchange between faultlinebased subgroups was not negatively related to faultline strength, i.e., teams with a stronger functional faultline did not have a lower ratio of between-subgroup information exchange. Rather than acting as a barrier between subgroups, functional faultlines did not show a significant influence on intersubgroup information exchange in our sample. This supports the assumption that interactions within a team meeting might not only be influenced by similarities and differences between team members (Polzer et al., 2002), but pre-given by structural requirements of the organization (Lawrence, 1997). Teams with long-term history might thus already have established interaction patterns within their meetings that are not influenced by faultline strength. Existing interactions can influence how group members perceive themselves and their subgroups: When the interaction between the subgroups is positive, it can foster the exchange of different ideas and viewpoints and thus unfold the positive effects of diverse groups (Gray et al., 2005). When the interaction between the subgroups is negative, intergroup bias, and resulting conflicts might be strengthened (Labianca et al., 1998). Following this notion, intersubgroup interaction in meetings would not necessarily be influenced by faultline strength, but interaction evolving within a team might instead activate or deactivate faultlines (Ren et al., 2015).

We hypothesized that increased intersubgroup information exchange would foster the team's implementation of actions discussed during the meeting. As hypothesized, we found positive effects of between-subgroup information exchange on number of measures as well as expert quality ratings of the measures discussed in the meeting. Groups with more information exchange between functional subgroups developed more measures to be taken after the meeting, which were rated as better by external experts. This indicates that communication within a team meeting-and especially communication between faultline-based functional subgroups-plays a role in team functioning. When functional subgroups engage in a lot of information exchange, solutions they develop might be more elaborated because of the different perspectives these subgroups bring together. This deep elaboration is especially important because potential obstacles can be discussed, and alternative plans can be evaluated (De Dreu et al., 2000). The positive impact of information exchange between subgroups on the quality of the action plan further shows that even though the faultlines and resulting subgroup formation might not be salient, information sharing and elaborating between functional subgroups is still beneficial because different viewpoints as well as different strategies to solve and discuss problems are present and taken into consideration by the whole team.

\section{Practical Implications}

Team leaders as well as team members can pay closer attention to the nature of interactions between functional subgroups to foster information exchange and elaboration. Following our findings, this would lead to a greater variety and quality of action plans, likely because the teams that deeply elaborated problems and solutions, their consequences and practicability in the organization and consequently have developed a shared understanding of the team's action plan.

Our findings show the relevance of exchanging and discussing information between functional subgroups, even if the subgroups are not as strongly separated by a faultline. This indicates that even small differences between subgroups could imply a diversity in knowledge between those subgroups and a resulting importance of knowledge integration. Team managers should thus not only be aware of strong faultlines and resulting subgroup formation, but also focus on effective intersubgroup communication in teams that are seemingly not as vulnerable to subgroup separation.

Our results can support meeting leaders design more effective meetings, for example by establishing communication rules or defining cross-cut tasks, that is, tasks that are assigned to members from different subgroups to ensure intersubgroup information exchange (Rico et al., 2012). Ineffective meetings add additional costs to the already high direct expenses associated with meetings due to increased productivity (MCI Inc., 1998). Studies show that meetings also put high time constraints on employees (Rogelberg et al., 2007). To avoid these negative side effects, meeting leaders should focus on strategies to use the time spent in meetings productively. Our results show that meeting outcomes are directly linked to communication between smaller knowledge-based subgroups. Meeting leaders should make sure that all team members have a chance to speak and that no strong communication routines emerge, for example one team member only offering ideas after a member of his or her subgroup has spoken and never speaking after a member of another subgroup has spoken.

The FCI can be employed to monitor communication between subgroups that are not necessarily faultline-based. The formulas provided can be applied to any team in which a clear allocation of members to subgroups is possible. This is especially relevant in the light of the current situation related to the Covid-19 pandemic, where many organizations rely at least partly on teleworking. Teams may thus be divided into colocated subgroups which can negatively impact group processes (Polzer et al., 2006). Closely monitoring intragroup processes may further support organizations in dealing with challenges related to communicating in teams that needed to adjust their communication routines.

\section{Limitations and Future Research}

Despite the considerable insights that the study provides, there are some limitations to our research that we want to discuss and that could offer starting points for future research. The study of subgroups requires complete data sets for all team members. While simulation studies show that missing values 
do not impact the calculation of faultline strength based on the ASW considerably (Glenz and Meyer, 2017), the allocation to a subgroup for each team member and the subsequent analysis of intersubgroup communication requires full data sets at least for the variables underlying the faultline calculation. We had to exclude seven teams due to incomplete data on educational level or tenure-a challenge that future studies in the organizational settings might also face, as participants might not indicate personal details due to data privacy concerns. Nevertheless, aiming for larger sample sizes when replicating our findings is commendable, especially when scholars want to integrate moderating variables into their models to further explore the proposed effects. Further, as noted above, adding the four lower order terms of the FCI as control variables in research models is advisable for mathematical reasons, but requires a certain sample size (Certo et al., 2020).

Further investigation is needed concerning the methodological properties of the FCI. Researchers could apply simulation studies to understand more closely how the FCI changes when group size and subgroup constellations vary. This could provide important insights into measures to be taken to adapt the FCI, depending on the study context and research questions at hand. Specifically, integrating configurational properties such as the number of subgroups and the variation of subgroup size into research on intersubgroup communication is relevant, as these properties will likely influence intersubgroup information exchange. As argued by research on subgroups (Carton and Cummings, 2012, 2013) the presence of more than two functional subgroups as well as a balance regarding subgroup size is beneficial for teams with functional subgroups, and is theorized to influence the consideration of knowledge in teams with functional faultlines. While this was not confirmed by our results, we still encourage future research to focus on these factors and to explore ways in which the number and balance of subgroups can be accounted for in the calculation of the FCI.

So far, we have only focused on one behavioral aspect of intersubgroup interaction when calculating the FCI: information exchange. Studies have shown that in general, negative interactions exert a greater influence on team outcomes than positive interactions (Baumeister et al., 2001; Kauffeld and Lehmann-Willenbrock, 2012). Hence, effects of negative interactions between subgroups might be especially important to outcomes such as implementation status or the quality of action planning, as they might hinder effective elaboration of task-relevant information and thus interact with the effects found in this study. Future research could further compare different aspects of communication behavior, for example comparing the FCIs of problem-focused vs. socioemotional interaction networks. The integration of behavioral codes obtained from coding schemes such as the act4teams coding scheme into the calculation of the FCI can extend our understanding of intragroup and intersubgroup processes. The interplay between different kinds of team and subgroup interactions should be considered and disentangled concisely in future studies.

Our results as well as research from other fields give rise to new research ideas that future studies could focus on. An aspect that is promising for future research is the integration of betweenteam communication when focusing on faultlines and subgroups (Bahmani et al., 2018). Researchers can adapt and apply the formulas used to calculate the FCI to assess communication between a set of groups within an organization. External knowledge acquisition is an important factor influencing team performance (Ancona and Caldwell, 1992). When studying teams embedded in an organization, it is likely that relations exist between individuals that do not belong to the same team. This especially relevant in the context of functional subgroups, as a strong identification with one's subgroup might strengthen team members' confidence to seek information that a subgroup needs from external sources (Cooper et al., 2013).

\section{CONCLUSION}

The present study discusses challenges and solutions to measuring communication between subgroups in the context of diversity faultlines. We present a measure of intersubgroup communication, the FCI, that can also be applied to any type of group falling into subgroups and propose a way to enrich the FCI with behavioral data. Our empirical application of the FCI extends our understanding of intersubgroup communication processes in meetings and their impact on meeting outcomes. The findings from our empirical investigation further underline the relevance of assessing intersubgroup communication. By this, we adhere to the call to integrate actual intersubgroup communication as mediating processes into research on the impact of faultlines. Our results highlight the relevance of intersubgroup information exchange for the implementation of actions that are taken within and following a meeting. Intersubgroup information exchange can be seen as an important process variable to include in future (meeting) research.

\section{DATA AVAILABILITY STATEMENT}

The data analyzed in this study is subject to the following licenses/restrictions: Data protection regulations of the research project. Requests to access these datasets should be directed to Simone Kauffeld, s.kauffeld@tu-braunschweig.de.

\section{ETHICS STATEMENT}

Ethical review and approval was not required for the study on human participants in accordance with the local legislation and institutional requirements. The patients/participants provided their written informed consent to participate in this study.

\section{AUTHOR CONTRIBUTIONS}

JS conceived the original idea for this article, performed all analyses, interpreted the results, and drafted the manuscript. SK collected the data, helped designing the study, gave constructive feedback, and contributed to writing and improving the manuscript. Both authors approved the manuscript to be published. 


\section{FUNDING}

This work was supported by the German Research Foundation (grant number KA2256/2-2).

\section{REFERENCES}

Adair, W. L., Liang, L. H., and Hideg, I. (2017). Buffering against the detrimental effects of demographic faultlines: the curious case of intragroup conflict in small work groups. Negot. Confl. Manage. Res. 10, 28-45. doi: 10.1111/ncmr.12087

Alsamadani, R., Hallowell, M., and Javernick-Will, A. M. (2013) Measuring and modelling safety communication in small work crews in the US using social network analysis. Construct. Manage. Econ. 31, 568-579, doi: 10.1080/01446193.2012.685486

Ancona, D., and Caldwell, D. (1992). Demography and design: predictors of new product team performance. Organ. Sci. 3, 321-341. doi: 10.1287/orsc.3.3.321

Bahmani, K., Semnani-Azad, Z., Adair, W. L., and Sycara, K. (2018). "Virtual negotiations between collocated diverse teams: the effect of intragroup faultlines on intergroup communication," in Proceedings of the 51st Hawaii International Conference on System Sciences (Hilton Waikoloa Village, HI), 698-706.

Baumeister, R. F., Bratslavsky, E., Finkenauer, C., and Vohs, K. D. (2001). Bad is stronger than good. Rev. Gen. Psychol. 5, 323-370. doi: 10.1037/1089-2680.5.4.323

Bezrukova, K., Jehn, K., Zanutto, E., and Thatcher, S. (2009). Do workgroup faultlines help or hurt? A moderated model of faultlines, team identification, and group performance. Organ. Sci. 20, 35-50. doi: 10.1287/orsc.1080.0379

Bezrukova, K., Thatcher, S., Jehn, K., and Spell, C. (2012). The effects of alignments: examining group faultlines, organizational cultures, and performance. J. Appl. Psychol. 97, 77-92. doi: 10.1037/a0023684

Bezrukova, K., Thatcher, S. M. B., and Jehn, K. A. (2007). "Group heterogeneity and faultlines: Comparing alignment and dispersion theories of group composition," in eds Conflict in Organizational Groups: New Directions in Theory and Practice, eds K. J. Behfar and L. L. Thompson (Northwestern University Press), 57-92.

Blau, P. M. (1977). Inequality and Heterogeneity: A Primitive Theory of Social Structure. New York, NY: Free Press.

Bonito, J. A., and Sanders, R. E. (2011). The existential center of small groups: members conduct and interaction. Small Group Res. 42, 343-358. doi: $10.1177 / 1046496410385472$

Borgatti, S. P., Everett, M. G., and Freeman, L. C. (1992). UCINET IV: network analysis software. Connections 15, 12-15.

Borgatti, S. P., Mehra, A., Brass, D. J., and Labianca, G. (2009). Network analysis in the social sciences. Science 323, 892-895. doi: 10.1126/science.1165821

Carton, A. M., and Cummings, J. N. (2012). A theory of subgroups in work teams. Acad. Manage. Rev. 37, 441-470. doi: 10.5465/amr.2009.0322

Carton, A. M., and Cummings, J. N. (2013). The impact of subgroup type and subgroup configurational properties on work team performance. J. Appl. Psychol. 95, 732-758. doi: 10.1037/a0033593

Certo, S. T., Busenbark, J. R., Kalm, M., and LePine, J. A. (2020). Divided we fall: how ratios undermine research in strategic management. Organ. Res. Methods 23, 211-237. doi: $10.1177 / 1094428118773455$

Cooper, D., Patel, P. C., and Thatcher, S. M. B. (2013). It depends: environmental context and the effects of faultlines on top management team performance. Organ. Sci. 25, 633-652. doi: 10.1287/orsc.2013.0855

Cronin, M. A., and Weingart, L. R. (2007). Representational gaps, information processing, and conflict in functionally diverse teams. Acad. Manage. Rev. 32, 761-773. doi: 10.5465/amr.2007.25275511

Cross, R., and Parker, A. (2004). The Hidden Power of Social Networks. Cambridge, MA: Harvard Business School Press.

De Dreu, C. K. W., Weingart, L. R., and Kwon, S. (2000). Influence of social motives on integrative negotiation: a meta-analytic review and test of two theories. J. Pers. Soc. Psychol. 78, 889-905. doi: 10.1037/0022-3514.78.5.889

Dougherty, D. (1992). Interpretive barriers to successful product innovation in large firms. Organ. Sci. 3, 179-202. doi: 10.1287/orsc.3.2.179

\section{ACKNOWLEDGMENTS}

We would like to thank Annika Meinecke for her valuable comments on an earlier version of this manuscript.

Fiske, S. T. (2000). "Interdependence and the reduction of prejudice," in Reducing Prejudice and Discrimination, ed S. Oskamp (Mahwah, NJ: Erlbaum), 115-135.

Gerpott, F. H., and Lehmann-Willenbrock, N. (2015). "How differences make a difference: the role of team diversity in meeting processes and outcomes," in The Cambridge Handbook of Meeting Science, eds J. A. Allen, N. LehmannWillenbrock, and S. G. Rogelberg (New York, NY: Cambridge University Press), 93-118. doi: 10.1017/CBO9781107589735.006

Gibson, C., and Vermeulen, F. (2003). A healthy divide: subgroups as a stimulus for team learning behaviour. Adm. Sci. Q. 48, 202-239. doi: 10.2307/35 56657

Glenz, A., and Meyer, B. (2017). "Selecting and weighting diversity attributes for faultline calculation," in Team Diversity II - New Insights on Faultines Within Diverse Teams, Symposium conducted at the EAWOP conference 2017, eds S. Stegmann and F. Schölmerich (Dublin).

Gloor, P. A., Fronzetti Colladon, A., Grippa, F., and Giacomelli, G. (2017). Forecasting managerial turnover through e-mail based social network analysis. Comput. Human Behav. 71, 343-352. doi: 10.1016/j.chb.2017.02.017

Gray, B., Susman, G., and Ren, H. (2005). Brokers' roles in knowledge management in teams: expertise, influence and schema conflicts. Acad. Manage. Proc. 2005, B1-B5. doi: 10.5465/ambpp.2005.18778529

Harrison, D., Price, K., Gavin, J., and Florey, A. (2002). Time, teams, and task performance: changing effects of surface- and deep-level diversity on group functioning. Acad. Manage. J. 45, 1029-1045. doi: 10.5465/3069328

Hogg, M. A., and Terry, D. J. (2000). Social identity and self-categorization processes in organizational contexts. Acad. Manage. Rev. 25, 121-140. doi: 10.5465/amr.2000.2791606

Homan, A. C., Hollenbeck, J. R., Humphrey, S., van Knippenberg, D., Ilgen, D. R., and Van Kleef, G. A. (2008). Facing differences with an open mind: openness to experience, salience of intragroup differences, and performance of diverse work groups. Acad. Manage. J. 51, 1204-1222. doi: 10.5465/amj.2008.357 32995

Horwitz, S. K., and Horwitz, I. B. (2007). The effects of team diversity on team outcomes: a meta-analytic review of team demography. J. Manage. 33, 987-1015. doi: 10.1177/0149206307308587

Huber, G. P., and Lewis, K. (2010). Cross-understanding: implications for group cognition and performance. Acad. Manage. Rev. 35, 6-26. doi: 10.5465/amr.35.1.zok6

Jehn, K. A., Northcraft, G. B., and Neale, M. A. (1999). Why differences make a difference: a field study of diversity, conflict, and performance in workgroups. Adm. Sci. Q. 44, 741-763. doi: 10.2307/2667054

Jehn, K. A., and Rupert, J. (2008). "Group faultlines and team learning: how to benefit from different perspectives," in Work Group Learning: Understanding, Improving and Assessing How Groups Learn in Organizations, eds V. I. Sessa and M. London (New York, NY: Taylor and Francis), 119-147.

Jiang, Y., Jackson, S. E., Shaw, J. B., and Chung, Y. (2012). The consequences of educational specialty and nationality faultlines for project teams. Small Group Res. 43, 613-644. doi: 10.1177/1046496412453943

Kauffeld, S. (2006). Self-directed work groups and team competence. J. Occup. Organ. Psychol. 79, 1-21. doi: 10.1348/096317905X53237

Kauffeld, S., and Lehmann-Willenbrock, N. (2012). Meetings matter: effects of team meetings on team and organizational success. Small Group Res. 43, 130-158. doi: 10.1177/1046496411429599

Kauffeld, S., Lehmann-Willenbrock, N., and Meinecke, A. L. (2018). "The advanced interaction analysis for teams (act4teams) coding scheme," in The Cambridge Handbook of Group Interaction Analysis, eds E. Brauner, M. Boos, and M. Kolbe (New York, NY: Cambridge University Press), 422-431. doi: $10.1017 / 9781316286302.022$

Kolbe, M., and Boos, M. (2019). Laborious but elaborate: the benefits of really studying team dynamics. Front. Psychol. 10:1478. doi: 10.3389/fpsyg.2019.01478 
Kozlowski, S. W. J. (2012). "Groups and teams in organizations: studying the multilevel dynamics of emergence," in Research Methods for Studying Groups and Teams a Guide to Approaches, Tools, and Technologies, eds A. Hollingshead and M. S. Poole (New York, NY: Routledge), 260-283.

Labianca, G., Brass, D. J., and Gray, B. (1998). Social networks and perceptions of intergroup conflict: the role of negative relationships and third parties. Acad. Manage. J., 41, 55-67. doi: 10.2307/256897

Lau, D. C., and Murnighan, J. K. (1998). Demographic diversity and faultlines: the compositional dynamics of organizational groups. Acad. Manage. Rev. 23, 325-340. doi: 10.5465/amr.1998.533229

Lau, D. C., and Murnighan, J. K. (2005). Interactions within groups and subgroups: the effects of demographic faultlines. Acad. Manage J. 48, 645-659. doi: 10.5465/amj.2005.17843943

Lawrence, B. S. (1997). Perspective-the black box of organizational demography. Organ. Sci. 8, 1-22. doi: 10.1287/orsc.8.1.1

Lehmann-Willenbrock, N., Allen, J. A., and Kauffeld, S. (2013). A sequential analysis of procedural meeting communication: how teams facilitate their meetings. J. Appl. Commun. Res. 414, 365-388. doi: 10.1080/00909882.2013.844847

Lehmann-Willenbrock, N., Rogelberg, S. G., Allen, J. A., and Kello, J. E. (2018). The critical importance of meetings to leader and organizational success. Organ. Dyn. 47, 32-36. doi: 10.1016/j.orgdyn.2017.07.005

Mangold (2010). INTERACT Quick Start Manual V2.4. Available online at: www.mangold-international.com

Mayo, M., Kakarika, M., Mainemelis, C., and Deuschel, N. T. (2017). A metatheoretical framework of diversity in teams. Hum. Relat. 70, 911-939. doi: $10.1177 / 0018726716679246$

MCI Inc. (1998). Meetings in America: A Study of Trends, Costs and Attitudes Toward Business Travel, Teleconferencing and Their Impact on Productivity. Available online at: http://e- meetings.verizonbusiness.com/ global/en/meetingsinamerica/uswhitepaper.php

Meinecke, A. L., and Lehmann-Willenbrock, N. K. (2015). "Social dynamics at work: meetings as a gateway," in The Cambridge Handbook of Meeting Science, eds J. A. Allen, N. Lehmann-Willenbrock and S. G. Rogelberg (New York, NY: Cambridge University Press), 325-356. doi: 10.1017/CBO97811075897 35.015

Mesmer-Magnus, J. R., and DeChurch, L. (2009). Information sharing and team performance: a meta-analysis. J. Appl. Psychol. 94, 535-46. doi: $10.1037 / \mathrm{a} 0013773$

Meyer, B., and Glenz, A. (2013). Team faultline measures: a computational comparison and a new approach to multiple subgroups. Organ. Res. Methods 16, 393-424. doi: 10.1177/1094428113484970

Meyer, B., Glenz, A., Antino, M., Rico, R., and Gonzalez-Roma, V. (2014). Faultlines and subgroups: a meta-review and measurement guide. Small Group Res. 45, 633-670. doi: 10.1177/1046496414552195

Meyer, B., and Schermuly, C. C. (2012). When beliefs are not enough: examining the interaction of diversity faultlines, task motivation, and diversity beliefs on team performance. Eur. J. Work Organ. Psychol. 21, 456-487. doi: 10.1080/1359432X.2011.560383

Meyer, B., Shemla, M., and Schermuly, C. C. (2011). Social category salience moderates the effect of diversity faultlines on information elaboration. Small Group Res. 42, 257-282. doi: 10.1177/1046496411398396

Miller, C. A., Schmer-Galunder, S., and Rye, J. M. (2010, August). "Politeness in social networks: Using verbal behaviors to assess socially accorded regard," Paper presented at the 2010 IEEE Second International Conference on Social Computing (Minneapolis, MN). doi: 10.1109/SocialCom.2010.85

Muthén, L., and Muthén, B. (2017). Mplus User's Guide, 8th Edn. Los Angeles, CA: Muthén \& Muthén.

Pettigrew, T. F. (1998). Intergroup contact theory. Annu. Rev. Psychol. 49, 65-85. doi: 10.1146/annurev.psych.49.1.65

Polzer, J. T., Crisp, C. B., Jarvenpaa, S. L., and Kim, J. W. (2006). Extending the faultline model to geographically dispersed teams: how co-located subgroups can impair group functioning. Acad. Manage. J.49, 679-692. doi: 10.5465 /amj.2006.22083024

Polzer, J. T., and Kwan, L. B. (2012). When identities, interests, and information collide: how subgroups create hidden profiles in teams. Res. Manag. Groups Teams 15, 359-381. doi: 10.1108/S1534-0856(2012)0000015017
Polzer, J. T., Milton, L. P., and Swann, W. B., Jr. (2002), Capitalizing on diversity: congruence in small work groups, Admin. Sci. Quar. 47, 296-324. doi: $10.2307 / 3094807$

Qu, X., and Liu, X. (2017). Informational faultlines, integrative capability, and team creativity. Group Organ. Manage. 42, 767-791. doi: 10.1177/1059601117716008

Reiter-Palmon, R., and Sands, S. (2015). "Creativity and meetings: do team meetings facilitate or hinder creative team performance?," in The Cambridge Handbook of Meeting Science. Cambridge Handbooks in Psychology, eds J. Allen, N. Lehmann-Willenbrock, and S. Rogelberg (Cambridge: Cambridge University Press), 585-614. doi: 10.1017/CBO9781107589735.025

Ren, H., Gray, B., and Harrison, D. A. (2015). Triggering faultline effects in teams: the importance of bridging friendship ties and breaching animosity ties. Organ. Sci. 26, 390-404. doi: 10.1287/orsc.2014.0944

Rico, R., Sánchez-Manzanares, M., Antino, M., and Lau, D. (2012). Bridging team faultlines by combining task role assignment and goal structure strategies. $J$. Appl. Psychol. 97, 407-420. doi: 10.1037/a0025231

Rico, R., Sánchez-Manzanares, M., Gil, F., and Gibson, C. (2008). Team implicit coordination processes: a team knowledge-based approach. Acad. Manage. Rev. 33, 163-184. doi: 10.5465/amr.2008.27751276

Roberge, M., and Van Dick, R. (2010). Recognizing the benefits of diversity: when and how does diversity increase group performance? Hum. Resour. Manage. Rev. 20, 295-308. doi: 10.1016/j.hrmr.2009.09.002

Rogelberg, S. G., Leach, D. J., Warr, P. B., and Burnfield, J. L. (2006). "Not another meeting!” Are meeting time demands related to employee well-being? J. Appl. Psychol. 91, 83-96. doi: 10.1037/0021-9010.91.1.83

Rogelberg, S. G., Scott, C. S., and Kello, J. (2007). The science and fiction of meetings. MIT Sloan Manage. Rev. 48, 18-21.

Sauer, N. C., and Kauffeld, S. (2013). Meetings as networks: applying social network analysis to team interaction. Commun. Methods Meas. 7, 26-47. doi: 10.1080/19312458.2012.760729

Sauer, N. C., and Kauffeld, S. (2016). The structure of interaction at meetings: a social network analysis. Z. Arb. Organ. Psychol. 60, 33-49. doi: 10.1026/0932-4089/a000201

Scott, C. W., Rogelberg, S. G., and Rhoades Shanock, L. (2012). Wasted time and money in meetings: increasing return on investment. Small Group Res. 43, 236-245. doi: 10.1177/1046496411429170

Stasser, G., and Titus, W. (1985). Pooling of unshared information in group decision making: biased information sampling during discussion. J. Pers. Soc. Psychol. 48, 1467-1478. doi: 10.1037/0022-3514.48.6. 1467

Straube, J., and Kauffeld, S. (2020). "Faultlines during meeting interactions: the role of intersubgroup communication," in Managing Meetings in Organizations (Research on Managing Groups and Teams, Vol. 20 eds A. L. Meinecke, J. A. Allen, and N. Lehmann-Willenbrock (Bingley: Emerald Publishing Limited), 163-183. doi: 10.1108/S1534-085620200000020008

Sunwolf, and Frey, L. R. (2005). "Facilitating group communication," in The Handbook of Group Research and Practice, ed S. Wheelan (Thousand Oaks, CA: Sage), 485-509. doi: 10.4135/9781412990165.n26

Thatcher, S. M. B., and Patel, P. C. (2012). Group faultlines: a review, integration, and guide to future research. J. Manage. 38, 969-1009. doi: 10.1177/0149206311426187

van der Kamp, M., Tjemkes, B. V., and Jehn, K. A. (2011). "Faultline activation and deactivation and their effect on conflict [Paper presentation]," in 24th Annual International Association of Conflict Management Conference (Istanbul). doi: 10.2139/ssrn.1866507

van Ginkel, W. P., and van Knippenberg, D. (2008). Group information elaboration and group decision making: the role of shared task representations. Organ. Behav. Hum. Decis. Process. 105, 82-97. doi: 10.1016/j.obhdp.2007.08.005

van Knippenberg, D., De Dreu, C. K. W., and Homan, A. C. (2004). Work group diversity and group performance: an integrative model and research agenda. J. Appl. Psychol. 89, 1008-1022. doi: 10.1037/0021-9010.89. 6.1008

van Knippenberg, D., Haslam, S. A., and Platow, M. J. (2007). Unity through diversity: value-in-diversity beliefs, work group diversity, and group identification. Group Dyn. Theory Res. Pract. 11, 207-222. doi: 10.1037/1089-2699.11.3.207 
van Knippenberg, D., and Schippers, M. C. (2007). Work group diversity. Annu. Rev. Psychol. 58, 515-541. doi: 10.1146/annurev.psych.58.110405. 085546

Vora, D., and Markóczy, L. (2012). Group learning and performance: the role of communication and faultlines. Int. J. Hum. Resour. Manage. 23, 2374-2392. doi: 10.1080/09585192.2011.61 6523

Williams, K. Y., and O'Reilly, C. A. (1998). Demography and diversity in organizations: a review of 40 years of research. Res. Organ. Behav. $20,77-140$.
Conflict of Interest: The authors declare that the research was conducted in the absence of any commercial or financial relationships that could be construed as a potential conflict of interest.

Copyright (c) 2021 Straube and Kauffeld. This is an open-access article distributed under the terms of the Creative Commons Attribution License (CC BY). The use, distribution or reproduction in other forums is permitted, provided the original author(s) and the copyright owner(s) are credited and that the original publication in this journal is cited, in accordance with accepted academic practice. No use, distribution or reproduction is permitted which does not comply with these terms. 